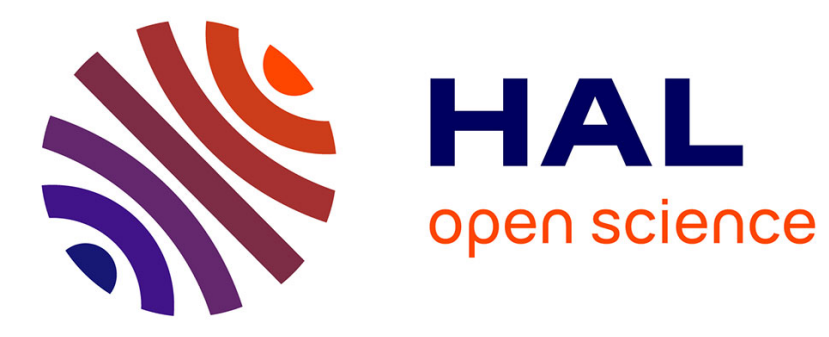

\title{
Underwater voice communications using digital techniques
}

\author{
B. Woodward, H. Sari
}

\section{To cite this version:}

B. Woodward, H. Sari. Underwater voice communications using digital techniques. Journal de Physique IV Proceedings, 1994, 04 (C5), pp.C5-469-C5-472. 10.1051/jp4:1994598 . jpa-00253093

\section{HAL Id: jpa-00253093 https://hal.science/jpa-00253093}

Submitted on 1 Jan 1994

HAL is a multi-disciplinary open access archive for the deposit and dissemination of scientific research documents, whether they are published or not. The documents may come from teaching and research institutions in France or abroad, or from public or private research centers.
L'archive ouverte pluridisciplinaire HAL, est destinée au dépôt et à la diffusion de documents scientifiques de niveau recherche, publiés ou non, émanant des établissements d'enseignement et de recherche français ou étrangers, des laboratoires publics ou privés. 


\title{
Underwater voice communications using digital techniques
}

\author{
B. WOODWARD and H. SARI
}

Department of Electronic and Electrical Engineering, Loughborough University of Technology, Leicestershire LE11 3TU, U.K.

\begin{abstract}
A digital signal processor (DSP) based voice communication system for divers with a $2400 \mathrm{bit} / \mathrm{s}$ transmission rate is described. Each speech signal frame is analysed using linear predictive coding (LPC) and the essential parameters such as amplitude, pitch period and digital filter coefficients are extracted. These parameters are transmitted through a water channel at a rate of $2400 \mathrm{bit} / \mathrm{s}$ by employing digital pulse position modulation (DPPM).
\end{abstract}

\section{INTRODUCTION}

The role of communications in diving is important not only from the point of view of information exchange and operational efficiency, but also to achieve greater safety. Since 1905, divers have been using voice communication systems, the early versions having a direct wire link between a hard hat diver on the bottom and a supervisor at the surface. Like the diving equipment of the time, these systems were simple and unsophisticated, and they were replaced in the 1960s by through-water acoustic systems which were more suitable for divers using Self Contained Underwater Breathing Apparatus (SCUBA).

There are several commercially available analogue wireless diver communication systems [1-3]. Some early systems used baseband communication methods in which acoustic signals were transmitted without modulation. However, these systems were affected by ambient acoustic noise which is dominant below $6 \mathrm{kHz}$ [4]. In most subsequent versions this problem has been obviated by shifting the spectrum of the baseband signals to a higher band and transmitting by using a modulation method such as amplitude modulation (AM), double sideband suppressed carrier (DSBSB), single sideband (SSB) or frequency modulation (FM). In view of its lower power consumption, SSB has been the most commonly employed technique [5]. When used underwater with acoustic signals for diver-to-diver or diver-to-surface communication, SSB has been shown to provide all the proven advantages of its counterpart for radio transmission. Nearly all the analogue systems that are presently on the market are virtually identical in their technical specifications and have not progressed beyond the technology of three decades ago. It is all too clear that the rapid development in digital signal processor technology and the advent of mobile communication systems has been completely ignored by the manufacturers of divers' voice communication systems. 


\section{FEASIBILITY OF DIGITAL SPEECH CODING FOR UNDERWATER COMMUNICATIONS}

In this research project speech data is transmitted by an acoustic transducer with a resonance frequency of $70 \mathrm{kHz}$, therefore a suitable kind of speech coding method has to be applied. After sampling the speech signal at a rate of $8 \mathrm{kHz}$, all the coded information representing this sample must be transmitted during the corresponding sampling period of $125 \mu \mathrm{s}$. There are several waveform quantization and encoding techniques for speech signals that have been widely used in telecommunications since the 1950s. In particular, we consider adaptive differential pulse code modulation (ADPCM).

In 1990, the Consultative Committee for International Telephone and Telegraph (CCITT) approved Recommendation G.727 for embedded ADPCM [6]. This specifies that the ADPCM algorithms can operate with $5,4,3$ or 2 bits per sample, i.e. at rates of $40,32,24$, and $16 \mathrm{kbit} / \mathrm{s}$. Because of the limitation of the projector, with a resonant frequency of $f_{o}=70 \mathrm{kHz}$, only $16 \mathrm{kbit} / \mathrm{s}$, or 4 cycles per bit, may be used for speech transmission. Therefore, the maximum time allowed to transmit each bit is less than $62,5 \mu \mathrm{s}$. In a noiseless channel, this rate is acceptable. But during transmission through water, the acoustic signal is seriously distorted by multipath propagation, which makes signal recovery very difficult. A method requiring a lower transmission rate must therefore be employed.

One possibility is to use one of the so-called parametric coding methods, which are recommended for low bit rate coding of speech signals $[7,8]$. These methods reduce the transmission rate to $400 \mathrm{bit} / \mathrm{s}$ by separating the excitation component of the speech from the spectral envelope component. The excitation is then characterized as either a pulse train for voiced sounds or noise for unvoiced sounds. The spectral envelope can be characterized by the parameters of a digital filter having the same transfer characteristics as the vocal tract.

Linear predictive coding (LPC) provides an accurate representation of the relevant speech parameters that can reduce transmission rates at the expense of a reduction in the quality of the reproduced speech [9]. In an LPC voice coder, efficient speech synthesis is achieved by transmitting frames of the speech waveform as a set of parameters, which are (i) the amplitude, (ii) a voiced/unvoiced decision and pitch period for voiced sounds, and (iii) the filter coefficients.

In the linear prediction representation, the speech signal is modelled as the output of an all-pole filter $\mathrm{H}(\mathrm{z})$.

$$
H(z)=\frac{G}{1+\sum_{k=1}^{p} a[k] z^{-k}}
$$

where $p$ is the number of modelled poles, $G$ is the gain of the filter and the $a[k] s$ are the coefficients characterizing the filter. Generation of the synthetic speech sequence requires a knowledge of the pitch period, the linear prediction coefficients and the power of the waveform in each speech frame. These parameters are computed by means of a TMS320C30 digital signal processor (DSP) [10]. The advantage of the LPC method is that the speech transmission rate is decreased to $2400 \mathrm{bit} / \mathrm{s}$, including error correction codes. In comparing the waveform and parametric coding methods, as can be seen from their transmission rates, the LPC method is superior to ADPCM and is therefore preferred for underwater acoustic transmission. 


\section{PULSE POSITION MODULATION FOR UNDERWATER SPEECH TRANSMISSION}

Digital modulation techniques, such as amplitude shift keying (ASK) [11], frequency shift keying (FSK) [12] and phase shift keying (PSK) [13] can be employed for underwater acoustic data transmission. As an alternative, pulse position modulation (PPM) is also an effective technique. The analogue PPM method is suited to serial data transmission systems [14]; its mode of operation is to sample the analogue signal and to transmit a short pulse that is delayed with respect to the sampling instant by an amount that is a linear function of the signal amplitude. The drawback is that during transmission a pulse can be seriously distorted by multipath propagation. Therefore estimating its relative position at the receiver is difficult, especially for high data rates.

Since the encoded speech signal is digital in nature, a digital pulse position modulation (DPPM) system is proposed. Because the speech parameters are digitally coded with a transmission rate of $2400 \mathrm{bit} / \mathrm{s}$ each 1-second of data is divided into frames consisting of 3 bits, i.e. 800 frames per second as shown in Fig.1. A frame, with a period of $T_{\mathrm{f}}=3 / 2400 \mathrm{~s}(1.25 \mathrm{~ms})$, is further divided into 10 slots, each of width $\mathrm{T}_{\mathrm{s}}=125 \mu \mathrm{s}$; these comprise 8 data slots which represent the eight possible 3-bit combinations of data and two guard band slots. A single PPM pulse is transmitted in each frame, allocated to one of the slots according to the digital information. The demodulation of such signals therefore requires two clock signals, one at the frame frequency of $800 \mathrm{~Hz}$ and the other at the slot frequency of $8 \mathrm{kHz}$.
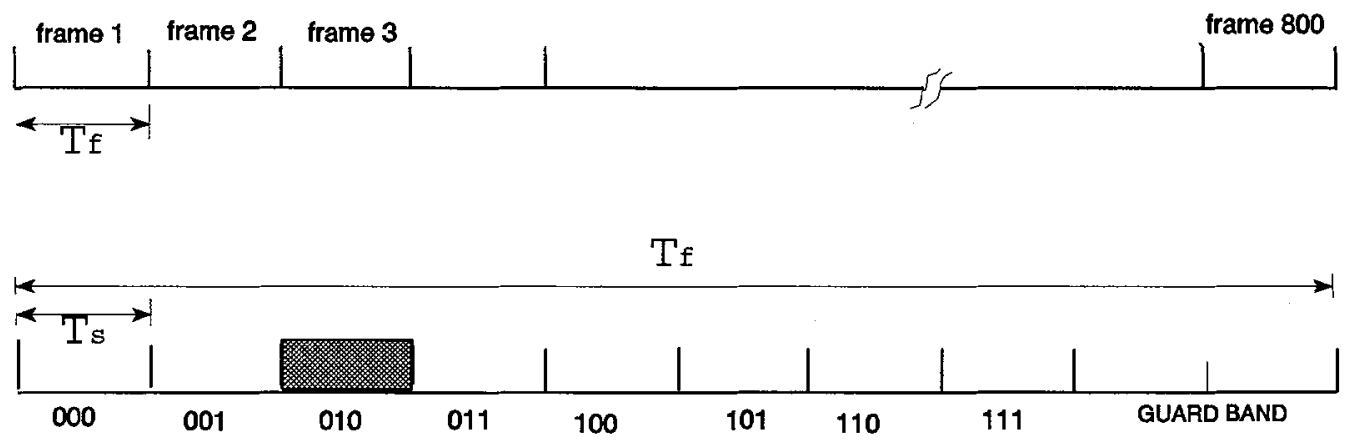

Fig.1. Digital PPM signal format for 8 data slots per sub-frame

Different synchronization schemes have been suggested in the literature for digital PPM transmission [15]. The system described here operates asynchronously, since there is no phase synchronism between the transmitter of one diver's system and the receiver of another. But in each separate system the transmitter and receiver are controlled by the same clock, which is simply a multiple of the slot frequency. Detection of the digital pulse position signal is achieved with the system shown in Fig.2.

Since a digital pulse representing the position of the data modulates a $70 \mathrm{kHz}$ sinusoidal waveform, a narrow bandpass filter is included in the receiver. The output of this filter is then passed through an envelope detector. Consider the situation when one diver starts speaking. The filter output of another diver's receiver first detects eight synchronization data pulses, i.e. $11111111_{2}$, which trigger a 4-bit counter running $8 \mathrm{kHz}$. The outputs of the counter control the integrators. When it counts to $100 \mathrm{O}_{2}$ the outputs of the eight integrators are compared to a threshold level set just above a level representing the amplitude of the unwanted multipath signal. During the pulse transmission interval the output of a particular integrator will be high and this becomes the input to a 8-to-3 decoder. The 3-bit decoder output is the transmitted parameter that is fed to the DSP-based LPC synthesizer. 


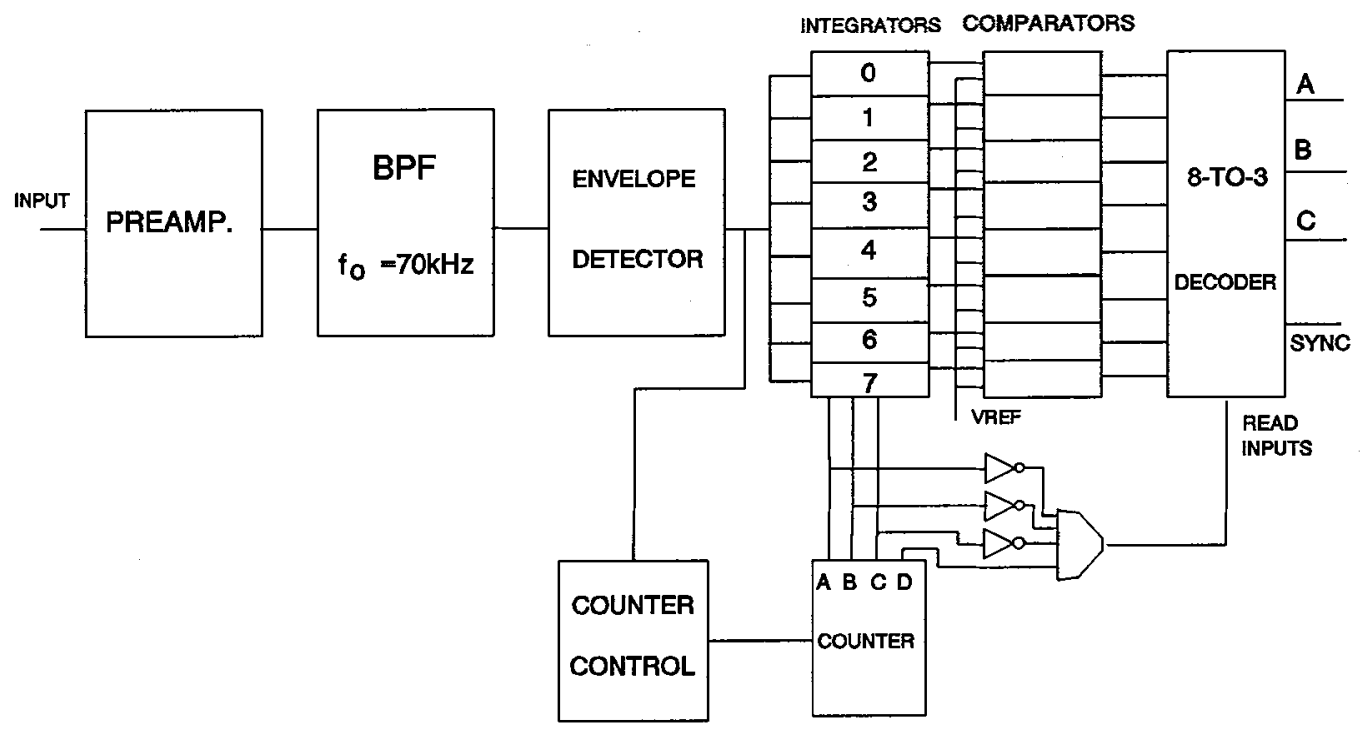

Fig.2 Analogue system for digital pulse position detection.

\section{REFERENCES}

[1] Overfield T., Underwater Systems Design, (March/April 1988) pp.8-13.

[2] Clark A., Underwater Systems Design, (January 1989) pp. 16-18.

[3] Peck M.J., Sea Technology, (1992) pp. 61-65.

[4] Virr L.E., IEE Proc 6 (1987) pp. 547-576.

[5] Woodward B., "Underwater Telephony: Past, Present and Future," Colloque De Physique 2 (1990) pp. C2 591-C2 594.

[6] Sherif M.H., Bowker D.O., Bertocci G., Orford B.A. and Mariano G.A., IEEE Trans. Comm., 2 (1993) pp. 391-399.

[7] Rabiner L.R. and Schafer R.W., Digital Processing of Speech Signals (Prentice-Hall, New Jersey 1978).

[8] Deller Jr. J.R., Proakis J.G. and Hansen J.H.L., Discrete-Time Processing of Speech Signals (MacMillan Publishing Comp., New York 1993).

[9] Makhoul J., Proc IEEE 63 (1975) pp.561-580.

[10] Tremain T.E., Speech Technology 1 (1982), pp. 40-49.

[11] Dawoud M.M., Halawani T.U. and Abdul-jauwad S.H. Int. J. Electronics 72 (1992) pp. 183-196.

[12] Brock D.C., Bateman S.C. and Woodward B., Ultrasonics, 24 (1986) pp. 183-188.

[13] Falahati A., Bateman S.C. and Woodward B., IEEE J. Ocean. Eng., OE-16 (1991) pp. 12-18.

[14] Riter S. and Boatrigth P.A., "Design considerations for a pulse position modulation underwater acoustic communication system," Digest IEEE Conf. Engineering in the Ocean Environment, Panama City, Fla., September 1970 pp. 21-24.

[15] Ling G. and Cagliardi R.M., IEEE Trans. Comm. COM-34 (1986) pp. 1202-1208. 